\title{
1 - 10 Mbar Laser-Driven Shocks Using the JANUS Laser
}

J. Dunn, D.F. Price, S.J. Moon, R.C. Cauble, P.T. Springer, $A . \mathrm{Ng}$

This article was submitted to:

12th Biennial International Conference of the APS Topical Group on "Shock Compression of Condensed Matter", Atlanta, Georgia, 24-29 June, 2001.

\section{August, 102001}

Lawrence

Livermore

National

Laboratory 


\section{DISCLAIMER}

This document was prepared as an account of work sponsored by an agency of the United States Government. Neither the United States Government nor the University of California nor any of their employees, makes any warranty, express or implied, or assumes any legal liability or responsibility for the accuracy, completeness, or usefulness of any information, apparatus, product, or process disclosed, or represents that its use would not infringe privately owned rights. Reference herein to any specific commercial product, process, or service by trade name, trademark, manufacturer, or otherwise, does not necessarily constitute or imply its endorsement, recommendation, or favoring by the United States Government or the University of California. The views and opinions of authors expressed herein do not necessarily state or reflect those of the United States Government or the University of California, and shall not be used for advertising or product endorsement purposes.

This is a preprint of a paper intended for publication in a journal or proceedings. Since changes may be made before publication, this preprint is made available with the understanding that it will not be cited or reproduced without the permission of the author.

This report has been reproduced directly from the best available copy.

Available to DOE and DOE contractors from the

Office of Scientific and Technical Information

P.O. Box 62, Oak Ridge, TN 37831
Prices available from (423) 576-8401

http: / / apollo.osti.gov/bridge/

Available to the public from the National Technical Information Service

U.S. Department of Commerce 5285 Port Royal Rd., Springfield, VA 22161 http: / / www.ntis.gov /

OR

Lawrence Livermore National Laboratory

Technical Information Department's Digital Library

http: / / www.llnl.gov/tid/Library.ht $\mathrm{ml}$ 


\title{
1 - 10 MBAR LASER-DRIVEN SHOCKS USING THE JANUS LASER FACILITY
}

\author{
James Dunn ${ }^{1}$, Dwight F. Price ${ }^{1}$, Stephen J. Moon ${ }^{1}$, Robert C. Cauble ${ }^{1}$, \\ Paul T. Springer ${ }^{1}$, and Andrew $\mathbf{N g}^{2}$ \\ ${ }^{1}$ University of California, Lawrence Livermore National Laboratory, Livermore, CA 94551 \\ ${ }^{2}$ Dept. Of Physics and Astronomy, University of British Columbia, Vancouver, Canada
}

\begin{abstract}
We report preliminary results using the Lawrence Livermore National Laboratory (LLNL) Janus laser facility to generate high pressure laser-driven shocks in the $1-10 \mathrm{Mbar}$ regime. These experiments address various issues, including shock steadiness, planarity, uniformity and low target preheat, important for making precision EOS measurements on a small $(\mathrm{E}<250 \mathrm{~J})$ laser facility. A brief description of the experimental techniques, target design and measurements will be given.
\end{abstract}

\section{INTRODUCTION}

The use of high-power laser pulses focused to high intensities is a well-established technique and one way to shock compress materials at the Mbar (100 GPa) level [1-3]. Many direct-drive laser experiments have been performed to characterize the principal Hugoniots of $\mathrm{Al}$ [4], $\mathrm{Cu}$ [5] and liquid $\mathrm{D}_{2}$ [6] to compare with equation-of-state (EOS). Indirect-drive experiments using laser beams focused in hohlraum cavities have also been conducted to improve the shock uniformity $[5,7,8]$.

Laboratory gas gun experiments have been conducted to benchmark Hugoniot measurements for various materials including $\mathrm{Al}, \mathrm{Cu}$, and Ta undergoing shock compression in the $0-5 \mathrm{Mbar}$ regime [9]. The gas gun type experiments have a number of important properties that allow precise determination of the shock pressure and EOS properties: (1) the initial conditions before the shock arrives are well characterized; (2) the launched shocks are planar, uniform, and steady; (3) the particle and shock velocities are accurately measured, the former determined by radiography of the impactor in flight. The number of gas gun shots, in common with large laser facilities, tends to be limited as a result of cost and setup time. Further review of gas gun experiments and additional references can be found in ref. [10].

Smaller laser facilities have the advantage of allowing a larger number of shots on target than the larger national facilities e.g. OMEGA and previously on NOVA. These laser shots are at lower shock pressures but more time can be dedicated to studying important details of the experiment, in particular, shock steadiness, planarity, uniformity and low target pre-heat. In this work, we address some of these issues for laser-driven shocks using the LLNL Janus laser facility in an initial set of experiments.

\section{EXPERIMENTAL DESCRIPTION}

The shock experiments were conducted on the LLNL Janus laser. This is a two-beam facility with pulse durations available from 100 ps to $7 \mathrm{~ns}$ (FWHM). For this work, a single beam of a $5 \mathrm{~ns}$ square pulse shape with a $\sim 200$ ps risetime was generated by utilizing a fast Pockels Cell switchout from a 7 ns (FWHM) Gaussian laser pulse. The 5 ns square pulse was determined from LASNEX hydrodynamic code simulations to give 
the desired combination of steady shocks and optimum pressures for the experiment. Output energy up to 220 J, $1064 \mathrm{~nm}$ wavelength, was available with 82.5\% delivered on target. Laser energy losses were mainly associated with the uncoated debris shield and the Phase Zone Plate (PZP) optic. The laser repetition rate was 1 shot/30 minutes with 8 shots/day being regularly achieved. This shot rate together with the total number of shots available is substantially higher than larger laser facilities and gas gun experiments.

The shock pressure is determined by the maximum intensity of the focused laser beam hence high pressures of $1-10 \mathrm{Mbars}$ or higher require intensities of $10^{13}-10^{14} \mathrm{~W} \mathrm{~cm}^{-2}$. A large focal spot, width $w$, is essential to launch a planar shock without shock erosion at the edges through a target of thickness $z$. Generally, $w>5 z$ is desired for good planarity in the center part of the laser focus driving the shock. For this experiment with target thickness $z$ of $\sim 100 \mu \mathrm{m}$ the highest pressure possible was less important than having large, smooth, planar shocks. A $\sim 500 \mu \mathrm{m}$ (FWHM) smoothed focal spot with a Super Gaussian $(n=3.4)$ profile was achieved by using a PZP optic in combination with an $f=34.3 \mathrm{~cm}$ focal length, $f \# 3$ aspherical lens [11], shown in Fig. 1. The PZP optic contains an array of Fresnel lenses which by sampling the laser spatial beam profile at different positions maps any low frequency beam non-uniformities into a uniform high-frequency speckle pattern at the focus $[12,13]$. Plasma ablation and shock propagation through the initial few microns of target smoothes the high frequency micron scale speckle leaving a planar uniform shock.

LASNEX simulations were performed to design a target to minimize target pre-heat at the sample before the arrival of the shock. This is shown in Fig. 2. The generic target design consists of a $10 \mu \mathrm{m} \mathrm{C}_{8} \mathrm{H}_{8}$ (parylene- $\mathrm{N}, \rho=1.11 \mathrm{~g} / \mathrm{cm}^{3}$ ) ablator layer coated onto a $25 \mu \mathrm{m} \mathrm{Al} \mathrm{(1100} \mathrm{alloy} \mathrm{or} \mathrm{high} \mathrm{purity)} \mathrm{pusher} \mathrm{layer} \mathrm{and}$

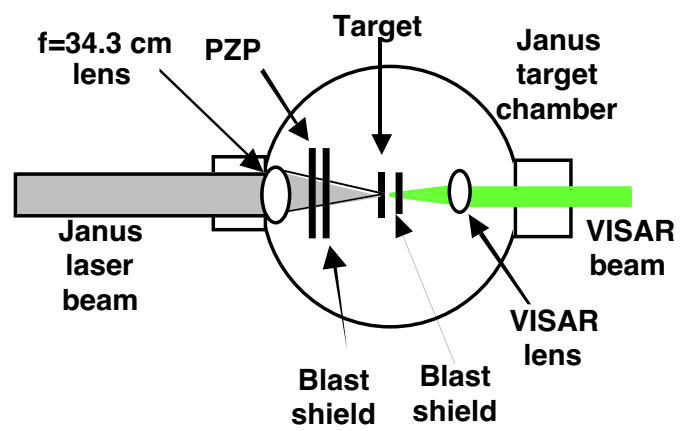

FIGURE 1. Setup showing Janus drive and VISAR probe. finally the sample to be studied. The low $Z \mathrm{CH}$ ablator gives good absorption of the laser energy into launching a shock but also minimizes the coupling of the laser energy into $\mathrm{keV} x$-rays which together with hot electrons from the laserproduced plasma can be a source of sample preheat. The simulations indicated that a $25 \mu \mathrm{m}$ thick Al pusher was sufficient to filter the keV x-rays and keep pre-heat at the pusher/sample interface to a minimum.

The main shock diagnostic was a Velocity Interferometer for Any Reflector (VISAR) probe beam that monitored the back surface of the target $[14,15]$. The velocity of the interface between the sample or the free surface can be measured and thus the particle velocity determined. A caveat is that the surface has to remain reflective during the motion. A powerful application of velocity interferometry is the ability to measure shock propagation inside a transparent medium if the shock pressure is high enough to metallize the material $[6,15]$. The VISAR instrumentation used here was similar to that of Celliers et al [15]. A 14 ns (FWHM), $532 \mathrm{~nm}$ wavelength beam from a

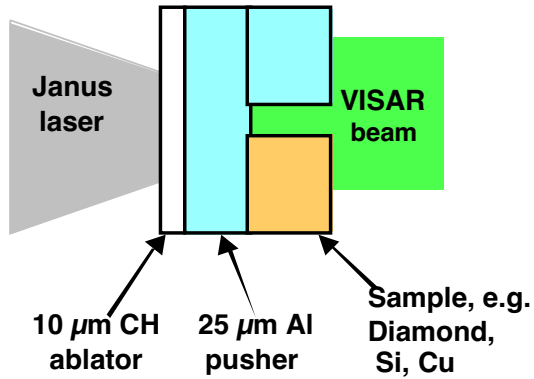

FIGURE 2. Target design showing $\mathrm{CH}$ ablator, $\mathrm{Al}$ pusher and sample to be shocked.

frequency-doubled $Q$-switched Nd:yttriumaluminum-garnet (YAG) laser was synchronized to the main Janus laser drive to probe the target back surface during and after the launch of the shock wave. A variety of etalon lengths were used from $0.125-8 \mathrm{~cm}$ giving a velocity sensitivity of $38-0.6 \mu \mathrm{m} / \mathrm{ns} /$ fringe, respectively. The back surface was imaged with $10 \times$ magnification using an $f=15 \mathrm{~cm}$ achromat and imaged onto the entrance slit of an S-20 photo-cathode Kentech or Hamamatsu streak camera. A time-resolved 1dimensional line image of the shock breakout at the back of the target was obtained.

A custom target wheel consisting of a $5 \mathrm{~cm}$ diameter disk with 12 target positions was 
designed. Each target sat in a $1 \mathrm{~cm}$ diameter disk with a $0.3 \mathrm{~cm}$ aperture on center to allow the laser drive beam onto the ablator side of the target. Eleven targets were mounted radially on the target wheel in machined recesses with a cross-wire alignment fiducial on the $12^{\text {th }}$ position. The target alignment and positioning could be performed offline. After each laser shot, an encoded stepper-motor rotation stage allowed the next target to be aligned giving a fast time between shots. An anti-reflection (AR) coated fused silica blast shield placed behind the target prevented target debris from coating the VISAR imaging lens.

\section{RESULTS AND DISCUSSION}

A simple target using $10 \mu \mathrm{m} \mathrm{CH}$ ablator vapordeposited on various Al pusher foil thicknesses of 25 $100 \mu \mathrm{m}$ was constructed to determine shock planarity. The critical element in achieving smooth, planar shocks was the focusing of the main optic ( $f \# 3$ asphere) and the Phase Zone Plate combination on the front of the target. The VISAR imaging achromat was used to focus the probe beam on the back surface of the target using a CCD imaging system built into the VISAR design. Then the same optic was used to focus the main Janus drive laser. Optimum (smooth) beam quality is achieved away from best focus [12]. Two sets of experiments were performed where the drive laser was focused in either the converging or diverging beam. The second diverging beam experiments gave more consistent, repeatable results for planar shocks.

A planar shock launched through a thin $\sim 25 \mu \mathrm{m} \mathrm{Al}$ foil was fairly straightforward as a result of the fast shock transit time $(\sim 2 \mathrm{~ns})$ and large $w / z$ ratio $(\sim 14)$. A thicker Al foil is more demanding to maintain shock planarity as a result of progressive erosion at the edges of the shock as it propagates through the material. Figure 3 shows the shock breakout for a $10 \mu \mathrm{m}$ $\mathrm{CH} / 100 \mu \mathrm{m} \mathrm{Al}$ foil driven at a laser intensity of $1.2 \times$ $10^{13} \mathrm{~W} \mathrm{~cm}^{-2}$ generating a shock pressure in the $1-1.5$ Mbar range. At the left side, the start of the Janus $5 \mathrm{~ns}$ square laser drive is indicated at $0 \mathrm{~ns}$ and the shock breakout of the Al foil is $8.7 \mathrm{~ns}$ later. At shock breakout the VISAR signal disappears simultaneously in a uniform and planar manner across about $400 \mu \mathrm{m}$ of the foil. The VISAR probe is still incident on the foil, as indicated by the intensity marker on the right. The loss of the VISAR signal may be due to a drop in the $\mathrm{Al}$ reflectivity from shock melting or absorption in a dense vapor layer close to the foil surface. Melting on the shock Hugoniot is predicted to begin at 1.2 Mbars and end at about 1.55 Mbars [16].

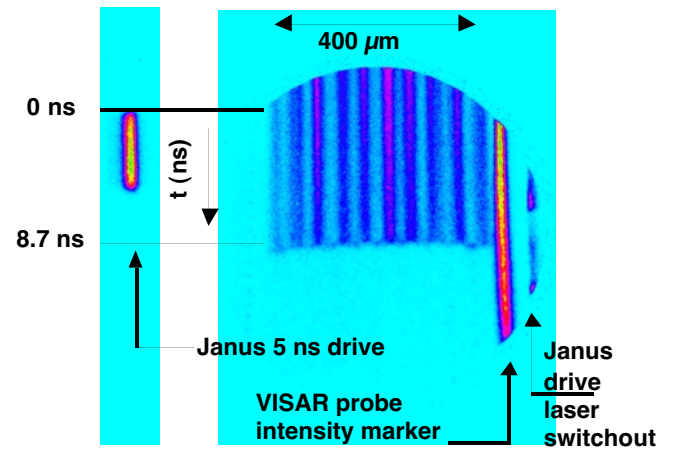

FIGURE 3. Streaked image showing planar shock breakout of $10 \mu \mathrm{m} \mathrm{CH} / 100 \mu \mathrm{m} \mathrm{Al}$ foil at $\mathrm{t}=8.7 \mathrm{~ns}$.

Al foil targets of different thickness, with and without $\mathrm{CH}$ ablator, were irradiated at $1.2 \times 10^{13}$ $\mathrm{W} \mathrm{cm}$ to determine the effectiveness of a low $Z$ ablator for reducing pre-heat. A $5.5 \mathrm{~cm}$ etalon was used in the VISAR to give a velocity sensitivity of $0.92 \mu \mathrm{m} / \mathrm{ns} /$ fringe. Motion of the back surface of the foil before shock breakout would indicate target pre-heat. Figure 4(a) shows that with the 10 $\mu \mathrm{m} \mathrm{CH}$ ablator on a $25 \mu \mathrm{m}$ foil no pre-heat could be detected before shock breakout at $4.05 \mathrm{~ns}$. The laser pulse starts at $2 \mathrm{~ns}$. This gives an upper limit on the pre-heat of $\Delta \mathrm{T} \sim 0.01 \mathrm{eV}$. Figure 4(b) for a thinner $12.5 \mu \mathrm{m} \mathrm{Al}$ foil with no $\mathrm{CH}$ ablator clearly shows fringe motion starting $0.48 \mathrm{~ns}$ before breakout and reaching a maximum velocity of $0.73 \mu \mathrm{m} / \mathrm{ns}$ at $3.0 \mathrm{~ns}$. Estimates of the pre-heat (a) $10 \mu \mathrm{m} \mathrm{CH} / 25 \mu \mathrm{m} \mathrm{Al}$

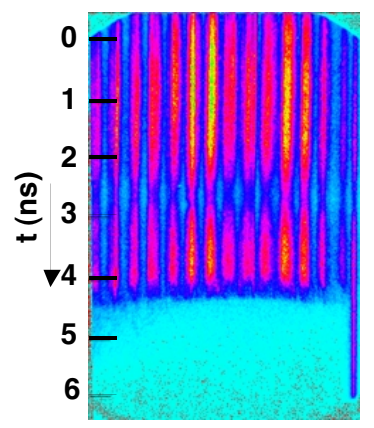

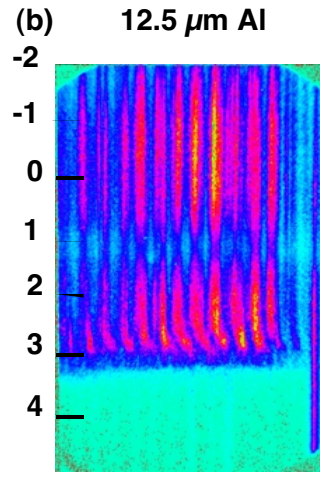

FIGURE 4. (a) Streaked image of $10 \mu \mathrm{m} \mathrm{CH} / 25 \mu \mathrm{m} \mathrm{Al}$ shows no back surface motion before breakout at $4.05 \mathrm{~ns}$. (b) $12.5 \mu \mathrm{m} \mathrm{Al}$ with no ablator showing back surface movement before breakout at $3.0 \mathrm{~ns}$. In each case the laser pulse starts at $2 \mathrm{~ns}$. Note that the change in the fringe reflectivity at $2.5 \mathrm{~ns}$ on Fig. 4(a) and at $1.0 \mathrm{~ns}$ on Fig. 4(b) is due to an artifact of the streak camera. 
level are $0.05-0.1 \mathrm{eV}$. Further analysis and modeling of these results are under way but the effect of the ablator in reducing pre-heat is demonstrated.

Shock velocity and steadiness were determined by measuring the time of shock breakout from a stepped $\mathrm{Al}$ target of maximum step thickness $125 \mu \mathrm{m}$ with a 10 $\mu \mathrm{m} \mathrm{CH}$ ablator. Figure 5 shows that for $10^{13} \mathrm{~W} \mathrm{~cm}^{-2}, u_{s}$ $=10.65 \mu \mathrm{m} / \mathrm{ns}$ and the velocity was constant to within $2.5 \%$. This corresponds to a shock pressure of 1.12 Mbar (based on the $u_{s}$ vs $u_{p}$ relations from ref. [9]). A maximum pressure of $1.6 \mathrm{Mbar}$ was achieved in $\mathrm{Al}$ in this experiment though higher pressure $\sim 4$ Mbar was achieved when higher density samples e.g. diamond were placed behind the $\mathrm{Al}$ pusher layer.

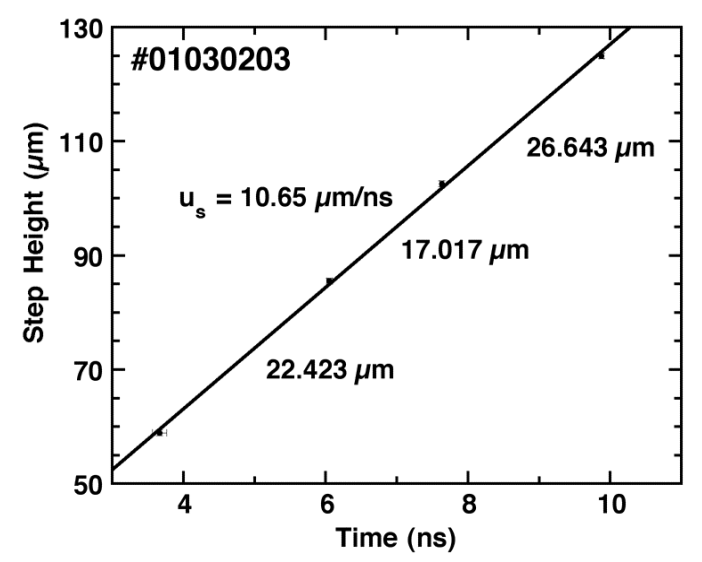

FIGURE 5. Shock breakout for Al step height versus breakout time.

\section{CONCLUSIONS}

We have conducted a few Megabar pressure experiments on the LLNL Janus facility at intensities $\sim 1-2 \times 10^{13} \mathrm{~W} \mathrm{~cm}^{-2}$. The target design has been optimized under these conditions to give steady, planar shocks with very low pre-heat. More detailed analysis and comparisons with simulations will be reported at a later date.

\section{ACKNOWLEDGMENTS}

The authors would like to thank Jim Emig, Derek Decker, and Al Ellis for their technical contributions to instrumentation and target fabrication in this research. This work was performed under the auspices of the US Department of Energy by the University of California
Lawrence Livermore National Laboratory under Contract No. W-7405-Eng-48.

\section{REFERENCES}

1. Veeser, L., and Solem, J., Phys. Rev. Lett. 40, 1391 - 1394 (1978).

2. Trainor, R. J., Shaner, J. W., Auerbach, J. M., and Holmes, N. C., Phys. Rev. Lett. 42, $1154-1157$ (1979).

3. Cottet, F., Romain, J. P., Fabbro, R., and Faral, B., Phys. Rev. Lett. 52, 1884 - 1887 (1984).

4. Ng, A., Parfeniuk, D., and Da Silva, L., Phys. Rev. Lett. 54, 2604 - 2607 (1985).

5. Benuzzi, A., Löwer, T., Koenig, M., Faral, B., Batani, D., Beretta, D., Danson, C., and Pepler, D., Phys. Rev. E. 54, 2162 - 2165 (1996).

6. Da Silva, L. B., Celliers, P., Collins, G. W., Budil, K. S., Holmes, N. C., Barbee Jr., T.W., Hammel, B. A., Kilkenny, J. D., Wallace, R. J., Ross, M., Cauble, R., Ng, A., and Chiu, G., Phys. Rev. Lett. 78, 484 - 487 (1997).

7. Löwer, T., Sigel, R., Eidmann, K. , Földes, I. B., Hüller, S., Massen, J., Tsakiris, G. D., Witkowski, S., Preuss, W., Nishimura, H., Shigara, H., Kato, Y., Nakai, S., and Endo, T., Phys. Rev. Lett. 72, 3186 - 3189 (1994).

8. Evans, A. M., Freeman, N. J., Graham, P., Horsfield, C. J., Rothman, S. D., Thomas, B. R., and Tyrrell, A.J., Laser and Particle Beams, 14, 113 - 123 (1996).

9. Mitchell, A. C., and Nellis, W. J., J. Appl. Phys. 52, 3363 - 3374 (1981).

10. Nellis, W. J., Encyclopedia. Appl. Phys. 18, 541 554 (1997).

11. Dunn, J., unpublished data (2001).

12. Stevenson, R. M., Norman, M. J., Bett, T. H., Pepler, D. A., Danson, C. N., Ross, I. N., Opt. Lett. 19, 363 (1994)

13. Koenig, M., Faral, B., Boudenne, J.-M., Batani, D., Benuzzi, A., and Bossi, S., Phys. Rev. E. 50, R3314 - 3317 (1994).

14. Barker, L.M., and Hollenbach, R.E., J. Appl. Phys. 43, 4669 (1972).

15. Celliers, P. M., Collins, G. W., Da Silva, L. B., Gold, D. M., and Cauble, R., Appl. Phys. Lett. 73, 1320 - 1322 (1998).

16. Moriarty, J. A., Young, D.A., and Ross, M., Phys. Rev. B 30, 578 - 588 (1984). 

University of California

Lawrence Livermore National Laboratory

Technical Information Department

Livermore, CA 94551 